Supplement of Geosci. Model Dev., 12, 4875-4899, 2019

https://doi.org/10.5194/gmd-12-4875-2019-supplement

(C) Author(s) 2019. This work is distributed under

the Creative Commons Attribution 4.0 License.

(c) (1)

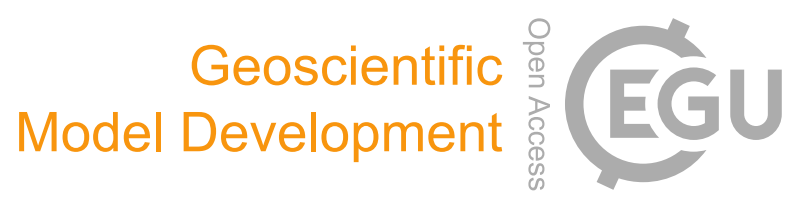

Supplement of

\title{
Assessment of the Finite-volumE Sea ice-Ocean Model (FESOM2.0) - Part 1: Description of selected key model elements and comparison to its predecessor version
}

Patrick Scholz et al.

Correspondence to: Patrick Scholz (patrick.scholz@awi.de)

The copyright of individual parts of the supplement might differ from the CC BY 4.0 License. 


\section{Supplement}

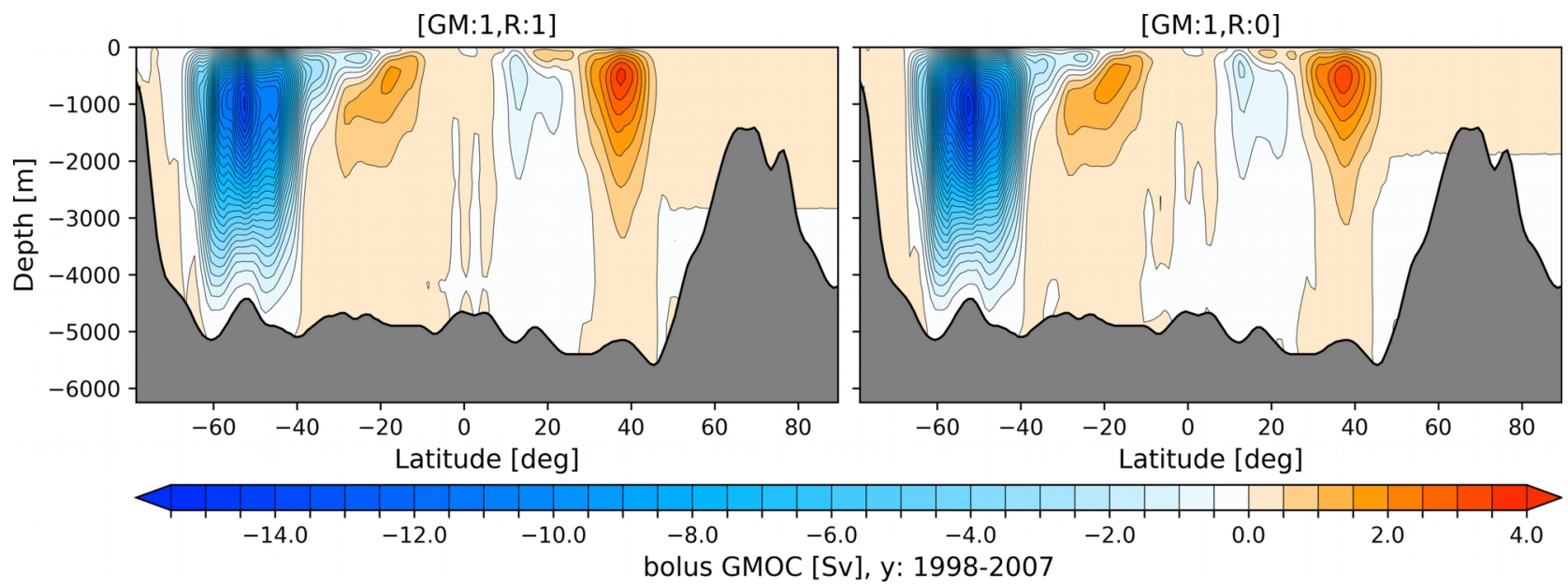

Figure S1: Global Meridional Overturning Circulation (GMOC) associated with the Gent McWilliams vertical bolus velocity, averaged for the time period 1998-2007, for the reference simulation (left) and the simulation in which the Redi diffusivity is set to zero (right). 

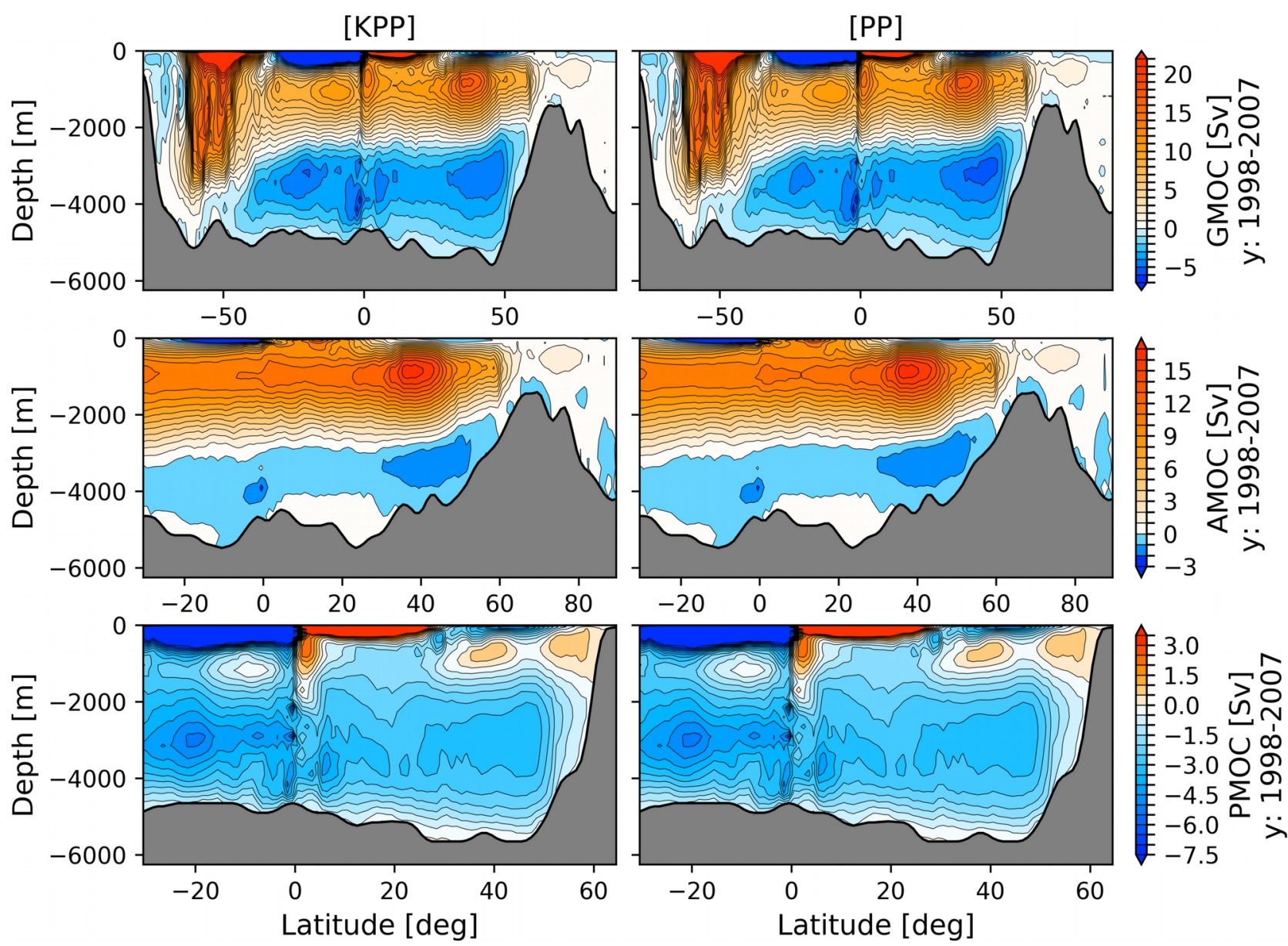

Figure S2: Global (GMOC, upper row), Atlantic (AMOC, middle row) and Indo-Pacific (PMOC, lower row) Meridional Overturning Circulation averaged for the time period 1998-2007 for the simulations with KPP (left column) and PP (right column) vertical mixing. 


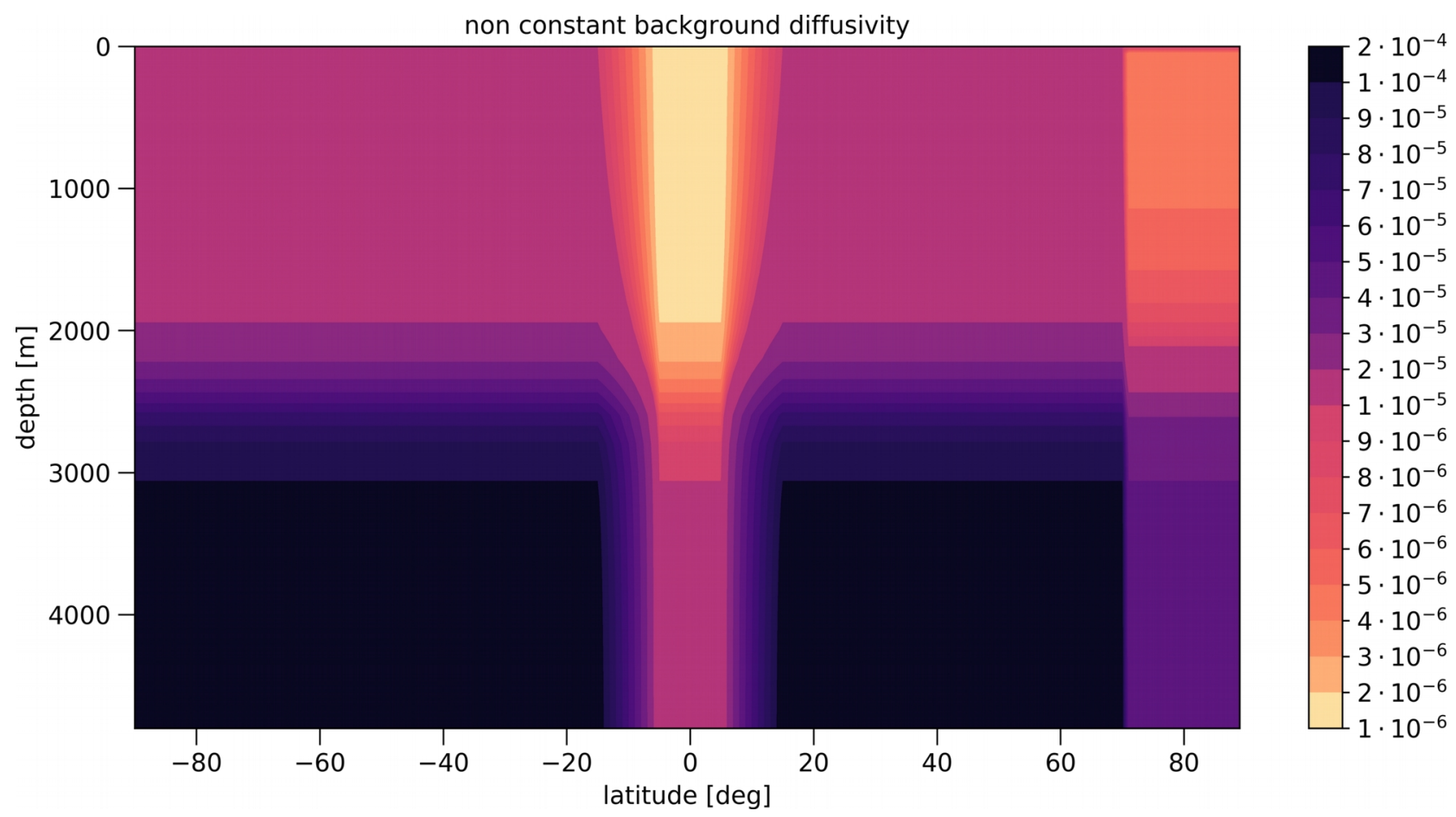

Figure S3: Depth and latitude dependent background vertical diffusivity used in PP and KPP vertical mixing scheme. 


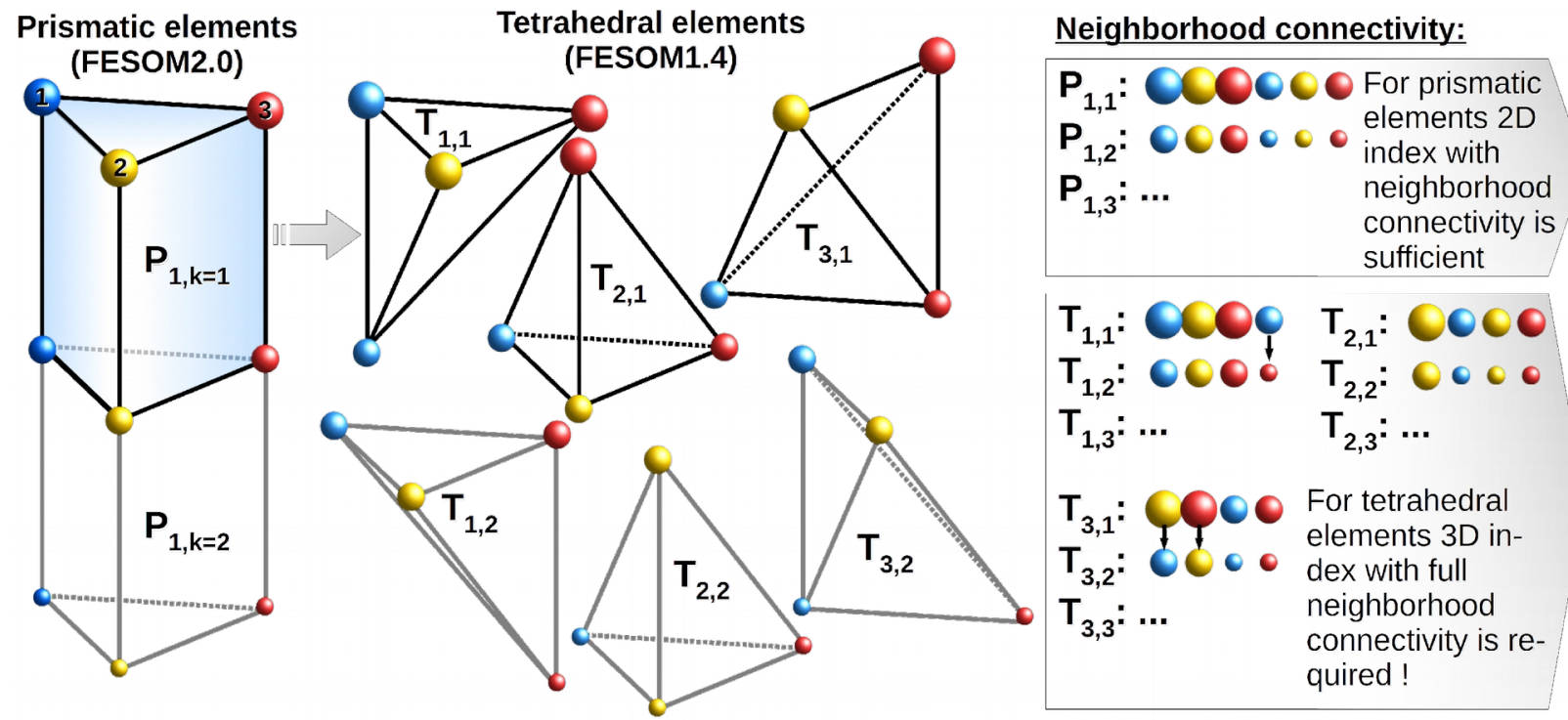

Figure S4: Schematic representation of neighborhood connectivity between prismatic and tetrahedral elements. 